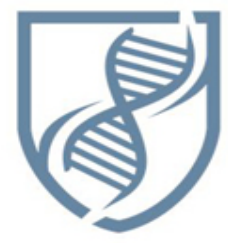

Journal of Bioscience and Applied Research
JBAAR

WWW.JBAAR.ORG

\title{
Adverse effects of monosodium glutamate on the reproductive organs of adult Female albino rats and the possible ameliorated role of carob (Ceratonia Siliqua)
}

\author{
Abd El-Fattah B. M. El-Beltagy ${ }^{1}$, Heba Attef Elghaweet ${ }^{2}$ \\ ${ }^{1}$ Zoology Dept., Faculty of Science, Damanhour University, Egypt. \\ ${ }^{2}$ Zoology Dept., Faculty of Science, Mansoura University, Egypt \\ (Corresponding author e.mail:beltagyaaa@yahoo.com)
}

\begin{abstract}
Monosodium glutamate (MSG) is a sodium salt of glutamic acid that enhances the flavor of certain foods. It plays an important role in the pathogenesis of anovulatory infertility. This study was carried out to evaluate the histological, histochemical as well as immunohistochemical effects of MSG on the ovaries, uterus and vagina of adult female Wistar rats and the possible ameliorative role of carob (Ceratonia Siliqua). In the present work, twenty- four Wistar rats were divided into four groups $(\mathrm{n}=6)$ : Control group received $0.5 \mathrm{ml}$ saline solution, carob-group, feeding on diet containing $5 \%$ carob powder, MSG- treated group received 400 $\mathrm{mg} / \mathrm{kg}$ b.wt and ameliorative group received MSG $400 \mathrm{mg} / \mathrm{kg}$ b.wt simultaneously with feeding on diet containing 5\% carob powder. In MSG treated rats, the serum estrogen level was significantly decreased. The histopathological results showed ovarian atretic follicles, fragmented oocyte, vascular congestion, and vacuolated stroma. The uterus exhibited a comparative reduction in the endometrial thickness and loss of endometrial glands associated with cellular hyperplasia and reduced vacuolated cells. In MSG treated group, the vaginal epithelium appeared relatively thin, folded and hypertrophied with sign of cornification. Histochemically, a weak reaction for PAS stain was remarked in investigated sections of MSG- treated rats. On the other side, an intense positive reaction for silver stain was recorded in the ovarian stroma and peripheral layers of atretic follicles as well as spreading in endometrium of uterus and lumina sheath of vagina. Immunohistochemically, MSG-treated group exhibited intense positive reaction for CD31and CD68 and activated caspase3 compared to carob-ameliorated MSG and the
\end{abstract}

control. The authors concluded that, feeding of MSGtreated group on diet containing 5\% carob powder led to marked amelioration of histopathological lesions induced in ovaries, uterus and vagina by MSG attributed to the biological benefits of its phytochemical components.

Keywords: MSG, Carob, histopathology, apoptosis, ovary, uterus, vagina.

\section{Introduction}

The female reproductive organs are very sensitive to the most harmful environmental agents (Bojanic et al., 2009). Most food additives are used either for preservation or enhancement of food taste (Moore, 2003).Monosodium glutamate (MSG) is a one of the widely used food additive (Zerasky, 2010), naturally occurring as nonessential amino acid (Yousef, 2011). It is synthesized by fermentation of sugar and beet sugarcane, or starch (Walker and Lupien, 2000). MSG is vastly used a food enhancer in most fast food-stuffs like vegetarian burgers, stuffed chicken, sausages, marinated meats, soups, potatoes chips and snacks and some frozen meals (Bojanic et al., 2009). Beyreuther et al. (2007) stated that the safe concentration of MSG in foods and its toxicity in human is still under considerations. It exerted harmful effects in animals (Mozes et al., 2004), even at comparatively lower doses in human and experimental animals (Biodun and Biodun, 1993; Egbuonu et al., 2009).

MSG could produce symptoms such as headaches, weakness, dizziness, sweating, numbness, and flushing. Furthermore, ingestion of MSG has been assumed to cause or trigger diverse conditions, including neuropathy, asthma, dermal hypersensitivity, cardiac arrhythmia, urticaria, and abdominal discomfort (Geha et al., 2001). Waer and Edress (2006) mentioned that, a daily oral dose of MSG (60-100mg) for one month increases the risk of 
fatty and fibrotic liver in male rats. Also, consumption of high doses of MSG may elevate the level of both liver and renal functions (Ortiz et al., 2006; Tawfik and Al-Badr, 2012).

MSG induced male infertility via inducing testicular hemorrhage and inhibition of spermatogenesis (Oforofuo et al., 1997) and reduction of sperm count and increase of sperm abnormities (Onakewhor et al., 1998). Higher doses of MSG led to damage of the hypothalamic nuclei and subsequently disturbance sin the hypothalamic-pituitary axis (Seo et al., 2010).. Female rats treated with MSG showed follicular degeneration of ovaries and disturbances of estrus cycle (Bojanić et al., 2009) and development of anovulatory infertility ( Eweka and Om'iniabohs, 2011). Zia et al.(2014) observed increased levels of estrogen and progesterone hormones in MSG-treated female rats.

Carob (Ceratonia siliqua) has been cultivated by Arabs in Mediterranean area. In Egypt, the carob pods are rich in sweet carbohydrate, dietary fiber, flavonoids and polyphenols especially tannins (Avallone et al. 1997; Makris and Kefalos 2004; Papagiannopoulos et al. 2004; Rasheed., 2006) and widely used as a popular drink. Following in-vitro studies, many authors such as Kumazawa et al. (2002) and Klaus et al. (2005) mentioned that carob showed a powerful antioxidant activity (Kumazawa et al. 2002; Klaus et al. 2005). Also, carobextract showed medicinal applications including inhibition of tumor cell proliferation (Corsi et al., 2002; Custódio et al., 2009), anti-diarrheal (Guggenbichler, 1983), antidiabetic (Edwards et al., 1987), anti-gastroesophageal reflux in infants (Wenzl et al.2003), and prevention of uterine bleeding (Mobli et al., 2015).

CD31 (cluster of differentiation 31) is a single chain transmembrane glycoprotein with a molecular weight of 130 to $140 \mathrm{KD}$, also defined as PECAM-1 (platelet endothelial cell adhesion molecule-1). It is expressed on the surface of platelets, monocytes, macrophages, and neutrophils and is a main component of the endothelial intercellular junction. CD31 plays a vital role in the adhesion sequences between endothelial cell and the inflammatory cells during infection facilitating leucocytes migration. It is also facilitated angiogenesis (DeLisser et al. 1997; Matsumura et al. 1997; Zhou et al., 1999). It is a good marker for benign and malignant vascular tumors (DeYoung et al. 1993).

CD68 is a glycosylated type I transmembrane glycoprotein, localized mainly within the endosomal compartment (Saito et al., 1991; Holnes et al., 1993) and used as a macrophage marker (Gough et al., 2001; Gottfried et al., 2008).

The present study was designed to evaluate the expected ameliorating role of the carob pods extract against the female infertility assessed by histopathological, histochemical and immunohistochemical investigations of MSG on ovary, uterus and vagina of female Wistar albino rats.

2 Materials and Methods

1. Chemicals: Monosodium glutamate (MSG) was purchased from Sigma Company in Cairo city, Egypt.
2. Carob powder: Dried carob pods were purchased from the market, and grinded to a fine powder.

3. Experimental groups:

In this study, twenty four healthy females' albino rats (2-3months old and weighed 150-180 g.) were obtained from animal house of Nephrology Medical Center, Mansoura University. All experiments are done in accordance with the guidelines for the Care and Use of Animals confirmed by Animal Experiments Committee in Mansoura University. The animals were maintained under standard laboratory conditions of 12 hours alternating light and dark cycles, room temperature of $25^{\circ} \mathrm{C}$ and good aeration. After the acclimation and observation periods, the animals were separated and divided into four groups $(n=6)$.

GroupI: (Control group) were fed on standard diet.

GroupII: Carob-feeding group, received food intake diet containing $5 \%$ of carob powder.

GroupIII: (MSC-treated group),received a daily oral dose of MSG (400mg/Kg. body weight) for a month according to Diniz et al. (2004) and Waer and Edress (2006).

GroupIV: (MSC-treated group fed on diet containing 5\% carob according to Ahmed (2010).

At the end of the treatment, the animals were anesthetized with diethyl ether, sacrificed, and the blood samples were collected, centrifuged and serum was separated. The animals were then dissected and to separate ovary, uterus and vagina.

4. Estimation of Serum Estrogen: Blood samples were collected from the animals each 5 day (with taking in consideration the phases of estrus cycle) and an enzyme based immunoassay (EIA) system was used to determine estrogen level by ELISA kit (Immunometrics (London, UK).

\section{Histological and Histochemical study:}

Ovary, uterus and vagina were fixed in $10 \%$ neutral buffered formalin for 24 hours. The tissues were dehydrated in ascending ethyl alcohol, cleared in xylene,

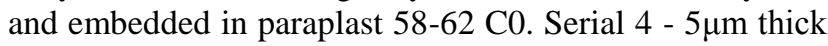
sections were cut and stained with hematoxylin and eosin (H\&E) for routine histological examination according to Carleton (1980). Other paraffin sections were stained with periodic acid-schiff (PAS) for demonstration of neutral mucins, glycogen, and other periodate reactive carbohydrates (Mc Manus, 1948) and to Gomori's methenamine silver histochemical stain for reticulin fibers (Culling et al., 1985).

\section{Immunohistochemical Demonstration of caspase} 3, CD31and CD68 activities.

Five $\mu \mathrm{m}$ thick paraffin sections were cut, mounted onto positively charged slides, de-waxed and hydrated in graded alcohol. Endogenous peroxidase activity was inhibited using $3 \% \mathrm{H}_{2} \mathrm{O}_{2}$ in methanol for $40 \mathrm{~min}$ at room temp. The tissue sections were retained at normal room temperature and processed for antigen retrieval by digestion in $0.05 \%$ trypsin $\left(\mathrm{pH} 7.8\right.$ ) for $15 \mathrm{~min}$ at $37^{\circ} \mathrm{C}$ specific to CD31and CD68 and in $10 \mathrm{mmol} / \mathrm{l}$ citrate buffer, $\mathrm{pH} 6.0$, in a steamer at $98^{\circ} \mathrm{C}$ for 45 min specific for 
caspase3. The slides were then incubated at 20C for 40 min with polyclonal rabbit anti-caspase-3 antibody (1:1000 dilution, PharMingen, San Diego, CA, USA), polyclonal antibodies against CD31 (platelet endothelial cell adhesion molecule, anti-PECAM-1, and dilution 1:100, cat. No. A1-82378) and monoclocal antibody against CD68 (Clone OTI8A4, Cat. No.TA802955). The slides were washed in PBS after each treatment, and counter stained with Mayer's hematoxylin.

\section{Results}

\section{Estrogen assay:}

Compared to the control, the serum estrogen levels were significantly decreased post- MSG- treatment $(\mathrm{p}<0.05)$. However, feeding MSG-treated group on diet containing 5\% carob exhibited improvement of estrogen level but was still non-significant decrease compared to either the control or carob-supplemented groups ( $\mathrm{p}>0.01)$. (Fig.1)

\section{Histopathological Observations:}

In control and carob-supplemented group, the ovaries possessed normal histological architecture structure with two distinct regions: an outer cortex full of growing follicles and an inner central medulla consisting of loose connective tissue containing blood vessels. The ovarian cortex was coated with germinal epithelium and enclosed underneath by primordial, primary, secondary, mature Graffian follicles. The growing follicles have wide cavities (antrum) full with liquor folliculi and lined by inner zona granulosa cells and outer theca lutein (Fig.2A).

In MSG treated rats, the surface of the ovary appeared irregular with invaginated germinal epithelium. There was a comparative decrease of developing follicles and increase of follicular atesia with degenerated oocytes and presence of granulosa cells with pyknotic nuclei and vacuolated cytoplasm. The ovarian medulla become vacuolated and infiltrated by numerous congested blood vessels. Diffused haemorhagic area and leukocyte infiltrations were remarked (Fig.2 A1).

In MSG-treated group fed on diet containing carob, there was a detected amelioration of the ovarian histological structure. The ovarian sections of MSG and Carob treated rats showed obvious amelioration for the previous histopathological findings (Fig.2 A2).

In control group, the uterus showed normal architecture for the endometrium layer. It consists of a single layer of simple columnar epithelium that comprised both types of ciliated and non-ciliated cells and an underlying thick layer of connective tissue stroma containing tortuous endometrial glands. Some of them open into the uterine lumen. The endometrial glands are simple tubular structures lined by columnar to cubical cells arise from the endometrial surface and traversed through the stroma, and contain a rich blood supply (Fig.2 B).

In MSG treated rats, the uterine endothelial cells showed obvious hyperplasia with vacuolated cytoplasm and few necrotic cells. The endometrial glands become comparatively reduced in number and atrophied (Fig.2 B1). In MSG and carob treated group the endometrial epithelium and glands were redifferentiated and was still less organized compared to the control (Fig.2 B2).

In control, the vagina composed of three layers; inner mucosa, middle muscularis and external adventitia. During pre-estrus cycle, the mucosa lined with stratified squamous non-keratinized epithelium and highly vascularized, elastic lamina propria (Fig.2 C). In MSG treated group, the vaginal epithelium appeared extensively lined with either pyknotic or vacuolated cells. Leukocytic infiltrations were remarked (Fig.2 C1). In carob supplemented MSG-treated group, there was a considerable improvement of lining mucosa and stroma cells and become more or less similar to the control (Fig.2 C2).

\section{Histochemical Observations: \\ 3.1. Histochemical reaction for PAS}

In control, the ovarian sections exhibited moderate PAS positive red staining affinity. The reaction was restricted to the granulosa cells,oocytes and and stroma cells (Fig.3A).

In experimental group treated with MSG, a weak PAS positive staining affinity observed in degenerated and atretic follicles and stromal tissue (Fig.3A1). In MSG treated group, fed on diet containing carob, the ovarian stroma as well as the follicular antrum showed moderate to strong positive PAS staining affinity (Fig.3A2).

The uterus of control possessed a weak to moderate PAS staining reaction especially in endometrial lining layer and endometrial glands (Fig.3B) however; this reaction become reduced in experimental group-treated with MSG (Fig.3B1). On the other hand, improved PAS staining affinity was recorded in both endometrial lining epithelium and endometrial glands of MSG-treated group fed on diet containing carob (Fig.2B2).

In control vaginal, a moderate PAS reaction was observed in vaginal epithelium (Fig.3C). However MSGtreated group, exhibited marked depletion of PAS staining affinity being become weaker in the vaginal epithelium (Fig.3C1). Compared to the control and MSG-treated group, the vaginal epithelial cells attained moderate PAS staining affinity in carob supplemented MSG-treated group (Fig.3C2).

\subsection{Histochemical reaction for silver stain:}

In control (Fig.4.A) and carob supplemented group (Fig.4.A2), the ovaries showed faint dark-brown reticulin fibers surrounding the ovarian follicles as well as throughout the ovarian stroma. However, ovaries of MSGtreated group showed dense dark-brown reticulin sheath around the atretic follicle and ovarian stroma after methenamine silver stain (Fig.4.A1).

The uterus of the control group (Fig.4.B) and carob-fed group (Fig.4.B2) exhibited faint silver staining reaction. However, MSG-treated group, possessed dense methenamine silver reaction especially in uterine stroma (Fig.4.B1).

In control, the vagina possessed weak methenamine silver stain (Fig.4.C). However, MSG-treated group, an intense dark-brown reaction was observed in mucosa region (Fig.4.C1). MSG-treated group fed on diet 
containing carob, revealed marked improvement and reduction silver staining affinity in the vaginal mucosa (Fig.4.C2).

\section{Immunohistochemical Observations:}

\subsection{Caspae3 activity:}

In control, the ovarian tissues exhibited weak immunoreactivity of caspase 3 (Fig.5.A). However increased immunoreactivity was observed in the granulosa cells of ovarian and atretic follicles of MSG- treated group (Fig.5.A1). Also, feeding MSG-treated group in diet containing carob, the ovarian cortex and medulla showed weak to moderate immunoreactivity for caspase3 compared to the control (Fig.5.A2).

The endometrial stroma of control rats possessed weak immunoreactivity of Caspse3 (Fig.5B). In experimental MSG- treated group, moderate to strong immunoreactivity was observed in the endometrial epithelial cells and in their surrounding glands (Fig.5.B1) and slightly decreased in MSG-treated group supplemented diet containing carob (Fig.5.B2).

In control vaginal mucosa, caspase 3 showed weak to negative immunohistochemical reaction (Fig.5.C). However, increased immune reaction was confined in vaginal mucosa and throughout stroma cells (Fig.5.C1). On the other side, the vaginal mucosa of MSG-treated group supplemented diet containing carob exhibited improved immunoreactivity compared to MSG-treated group and control rats (Fig.5.C2).

\subsection{D31 activity:}

In control, the fine blood vessels of the ovarian stroma exhibited weak positive expression for CD31 (Fig.6.A). However, in MSG-treated rats exhibited an increase of immune reaction in stroma blood vessels and around the ovarian follicle (Fig.6.A1). In contrast, MSG-treated group fed on diet containing carob possessed a weak immunohistochemical reaction in both the periphery of ovarian follicles and the ovarian stroma (Fig.6.A2).

Also, the uterine endometrium of control possessed weak to moderate positive reaction for CD31 (Fig.6.B) comparing to more reaction post-MSG-treatment (Fig.6.B1). In contrast, improved weak reaction was remarked in MSG-treated group fed on diet containing carob (Fig.6.B2).

The blood vessels of the vaginal mucosa of control (Fig.6.C) exhibited very weak immunoreactivity for CD31. In contrast, intense immune reaction was observed in the vagina of MSG treated group (Fig.6.B1) and improved post-feeding on diet containing carob (Fig.6.C2).

\subsection{CD68 activity:}

In MSG-treated groups, the immunohistochemical reaction of CD68 is overexpressed in leukocytes infiltrated around the vessels of ovarian stroma and the granulosa cells of ovarian follicles (Fig.7 A1). In contrast MSGtreated group fed on diet containing carob, the ovarian vessels expressed very weak immunohistochemical reaction (Fig.7.A2) compared to the control (Fig.6.A).

In endometrial mucosa of control, the immunohistochemical reaction of CD68 was slightly weak in leukocytes (Fig.7.B). However MSG- treated group showed a remarkable increase in the endometrial stroma (Fig.7.B1). In contrast, slightly weak to negative immune reaction was observed in the endometrial stroma of MSGtreated group feeding on diet containing carob compared to the control (Fig.7.B2). Similar findings were explained in the vaginal mucosa of MSG-treated group compared to control and those fed on diet containing carob (Fig.6.C, C1 \&C2).

\section{Discussion}

Recently, MSG is commonly used as a food enhancer in many foodstuffs and this may contribute to developmental reproductive defects in male (Oforofuo et al, 1997) and female rats (Oforofuo et al., 2015). MSG plays a critical role in the pathogenesis of anovulatory infertility (Bojanic, 2009; Eweka and Om iniabohs, 2011) however the mechanism of MSG action has not been yet illustrated. The present work revealed that, the ovarian, uterine and vaginal sections of MSG treated rats exhibited considerable histopathological changes. The ovaries possessed drammatic increase of follicular atresia, degeneration of oocytes and pyknotic and vacuolated granulosa. Some of the granulosa exfoliated within the antral cavity. Leukocyte infiltration and congestion of blood vessels were observed. These results were in accordance with those of Eweka and Om iniabohs (2011) and Oforofuo et al. (2015) who reported similar follicular damage in rat ovaries post-MSG- treatment. Al-mosaibih (2013) attributed the MSG-related degeneration of ovarian follicles to the increase of oxidative stress. Vacuolation of the granulosa cells post MSG-treatment may represent a type of cellular defense against its toxicities ( Ali et al.,2014) as well as a source of accumulating toxic agents interfering with its biological interactions in cell metabolism (Cheville,2009). Congestion of ovarian blood vessels may be resulted from the inhibition of MSG to prostaglandin synthesis maintaining blood flow (Oforofuo et al., 2015). Also, the drastic effects of MSG on ovarian tissues were confirmed by a marked depletion of serum estrogen level which consequently induced severe histopathological lesions in endometrium. 


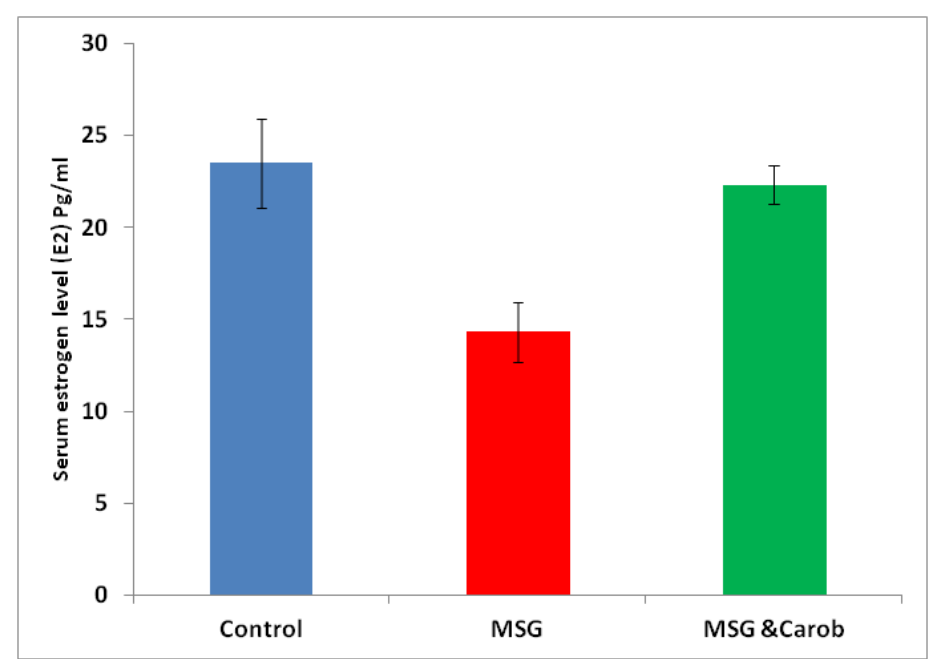

Fig.1. Serum estrogen (E2) level (Pg/ml) of MSG- treated group and those fed on diet containing carob compared to control. Significantly decreased in MSG-treated group at $\mathrm{P}<0.05$.

These were explained by vacuolated endometrial lining cells infiltrated by degenerated cells as well as apparent numerical reduction and shrinkage of endometrial glands. The present finding agree with the work of (Miskowiak et al., 2000; Wahyuni et al., 2014) whom revealed reduced endometrial thickness after MSG-treatment.

Also, disruption of estrogen level may contribute to the development of disorganized vaginal mucosa of MSGtreated rats. There was a comparative reduction and thinning of vaginal mucosa and decreased glandular function assessed by depleted its glycogen content. Several studies declared that declined blood estrogen level is accompanied by atrophic vaginitis with decreased glycogen secretion (Pandit and Ouslander, 1997; Bachmann et al., 2000).

Depletion of carbohydrates content was also recorded in ovary (Ali et al., 2014) and renal tissue (Afeefy et al, 2012) of MSG-treated rats. Altered ovarian carbohydrate inclusions may be resulted from disturbances of glycolytic enzyme pathways inducing disturbances of carbohydrate synthesis (El-Sherbiny et al., 1995). Bachmann et al. (2000) mentioned that decreased estrogen level represent the structural element of depleted glycogen secretion from the vaginal and endometrial mucosa.

Silver stained sections of MSG- treated ovaries stained with methenamine-silver stain showed a comparative increase of reticular fibers in the theca layer and within the ovarian stroma. Also, reticular fibrosis was observed in the endometrial stroma and vaginal mucosa. Following studying the effects of MSG on bone marrow (McCarthy,1985; Johnston et al. ,1995) and liver (Waer and Edress,2006), the authors reported accumulation of reticular fibers (fibrosis) attributed to overexpression of plateletderived growth factor and tumor growth factor- $\beta$, the potent stimulators of fibroblast differentiation.
Apoptosis is an essential physiological process by which multi-cellular organisms remove unwanted cells to ensure proper development and maintain cellular homeostasis. Caspases are critical mediators of programmed apoptosis and serve as markers of apoptosis (Tnroh et., 1998; Logs et al., 1999). Among them, caspase-3 is a frequently activated death protease, catalyzing the specific cleavage of many key cellular proteins so it is known as a strong apoptotic marker (Porter and Janicke 1999). Previously, Pavlovic et al. (2007) reported that MSG administration increase cellular apoptosis through downregulation of Bcl-2 protein as this compound prevent apoptosis by sequestering proforms of death-driving cysteine proteases or caspases. Our immunohistochemical results on MSG treated rat's revealed mild to strong expression of cleaved caspase3 activity in the zona granulsa cells of ovarian follicle, uterine endometrial cells and vaginal epithelial cells. Expression of apoptosis in the follicular granulosa cells may reflect disturbances in ovulation cycle. Many studies hypothesized that increased incidence of apoptotic cells in the follicular granulosa, is an indication for pre-ovulatory process and subsequently ensuing early luteinization process leading to infertility (Kugu et al., 1998; Matikainen et al., 2001; Glamoclija et al., 2004).

Normally during the estrus cycle, the uterine and vaginal epithelium possessed increased average of apoptotic cells facilitated banishment of cell debris (Sato et al., 1997; (Joswig et al., 2003). The present findings revealed that MSG- treated exhibited comparative increase of apoptotic cells in the investigated organs compared to control and those treated with MSG and supplemented diet containing carob. The present findings agree with the work of Wahyuni et al. (2014) on the uterine endometrium of MSG- treated rats. 

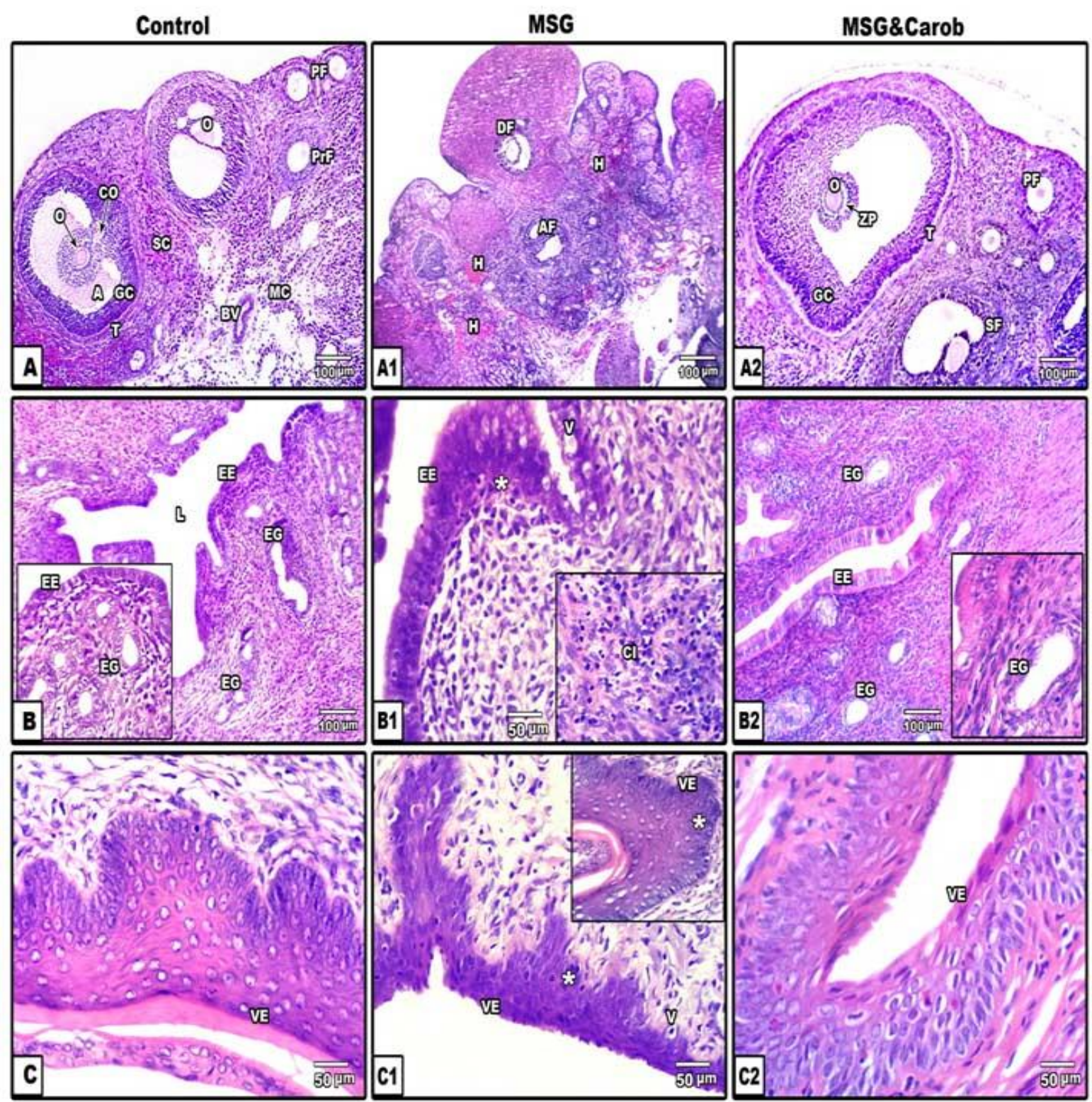

Fig.2

Fig.2. Photomicrographs of histological sections of ovaries (A, A1\&A2), uterine (B, B1\&B2) and vagina (C, C1\&C2) of control (A-C), MSG-treatment (A1-C1) and MSG-fed diet containing carob (A2-C2). Note that MSG-treated group A1: the ovary showing degenerated follicle (DF), atretic follicles (AF), medullary internal hemorrhage (H) and presence of numerous vacuoles (V). B1: uterus showing hyperplastic lining cell (star), leukocytic infiltration (CI) of uterine endometrium. C1: vagina showing atrophied and thinning vaginal epithelium (VE). Also, Note remarkable improvement of histological structure in the ovary (A2), uterus (B2) and vagina (C2) of MSG-fed diet containing carob. H\&E stain. Abbreviations, antrum(A), cumulus oorphus(CO), oocyte(O),primordial follicle(PF), primary follicle(PrF), secondary follicle (SF), granulose cells(GC), follicular theca(T), stromal cells (SC), blood vessels(BV) zona pellucid(ZP),endometrial epithelium(EE),endometrial glands (EG), endometrial lumen (L). 


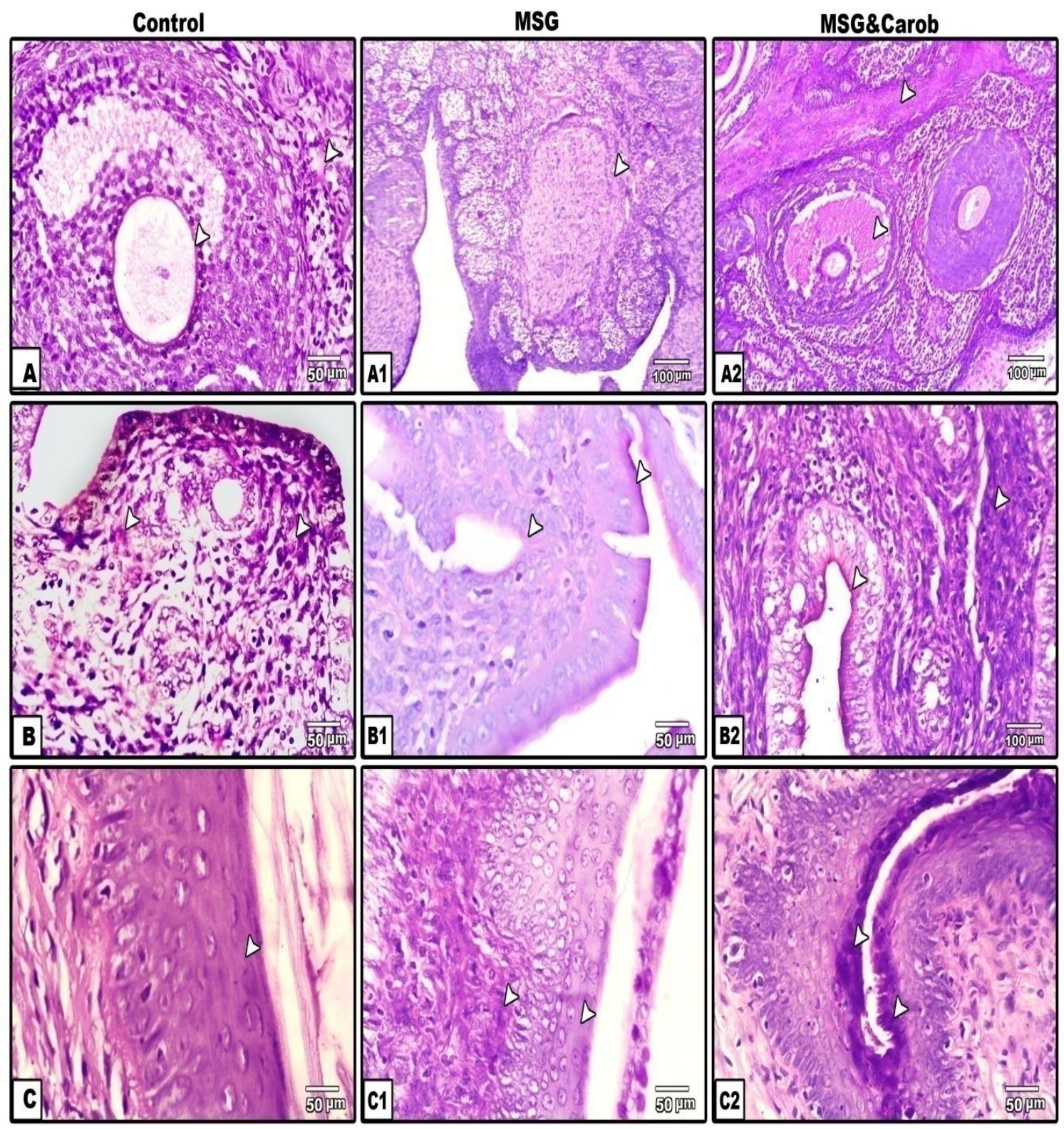

Fig.3

Fig.3.Photomicrographs through the ovarian (A, A1\&A2), uterine (B, B1\&B2) and vagina (C, C1\&C2) sections of control (A, B \& C), MSG-treatment (A1-C1) and MSG-fed diet containing carob (A2-C2) stained with PAS. Note moderate reaction in all histological sections of control (A, B\&C), a very weak PAS reaction in MSG-treatment (A1, B1\&C1), and improved PAS expression in MSG\& carob-fed group (A2, B2 \&C2). The arrow heads indicate the degree of PAS reactivity. PAS stain. 


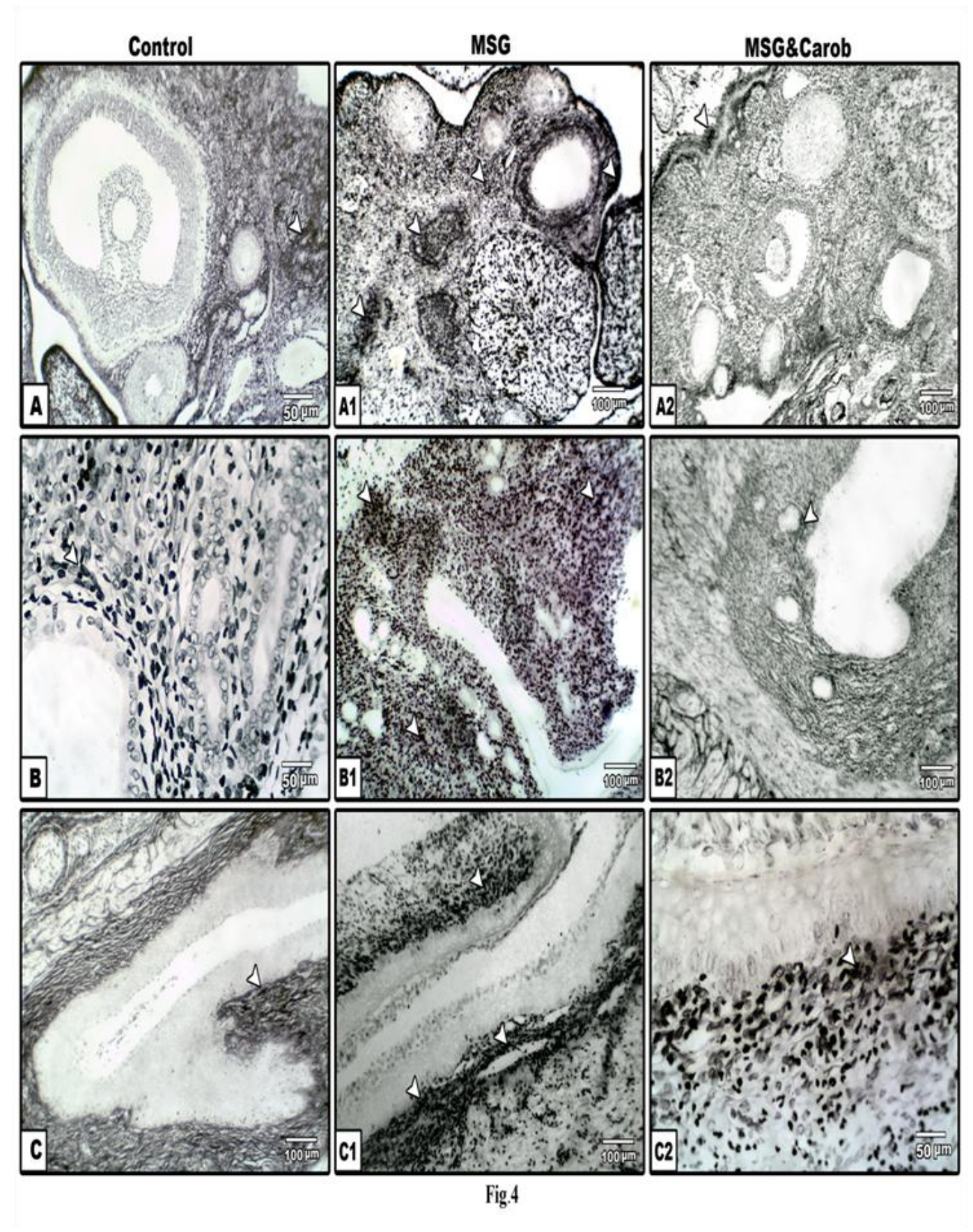

Fig.4.Photomicrographs through the ovarian (A, A1\&A2), uterine (B, B1\&B2) and vaginal (C, C1\&C2) sections of control (A, B, C), MSG-treatment (A1-C1) and MSG-fed diet containing carob (A2-C2) stained with Gomori's silver impregnation technique. Note a weak to moderate blackish reticular fibers in control group (A, B\&C), more accumulation of reticular fibers in MSG-treated group (A1, B1\&C1) and improvement of reticulin accumulation of MSG-fed diet containing carob (A2-C2). The arrows heads indicate the degree of reticulin fibrosis. Gomori's silver stain 

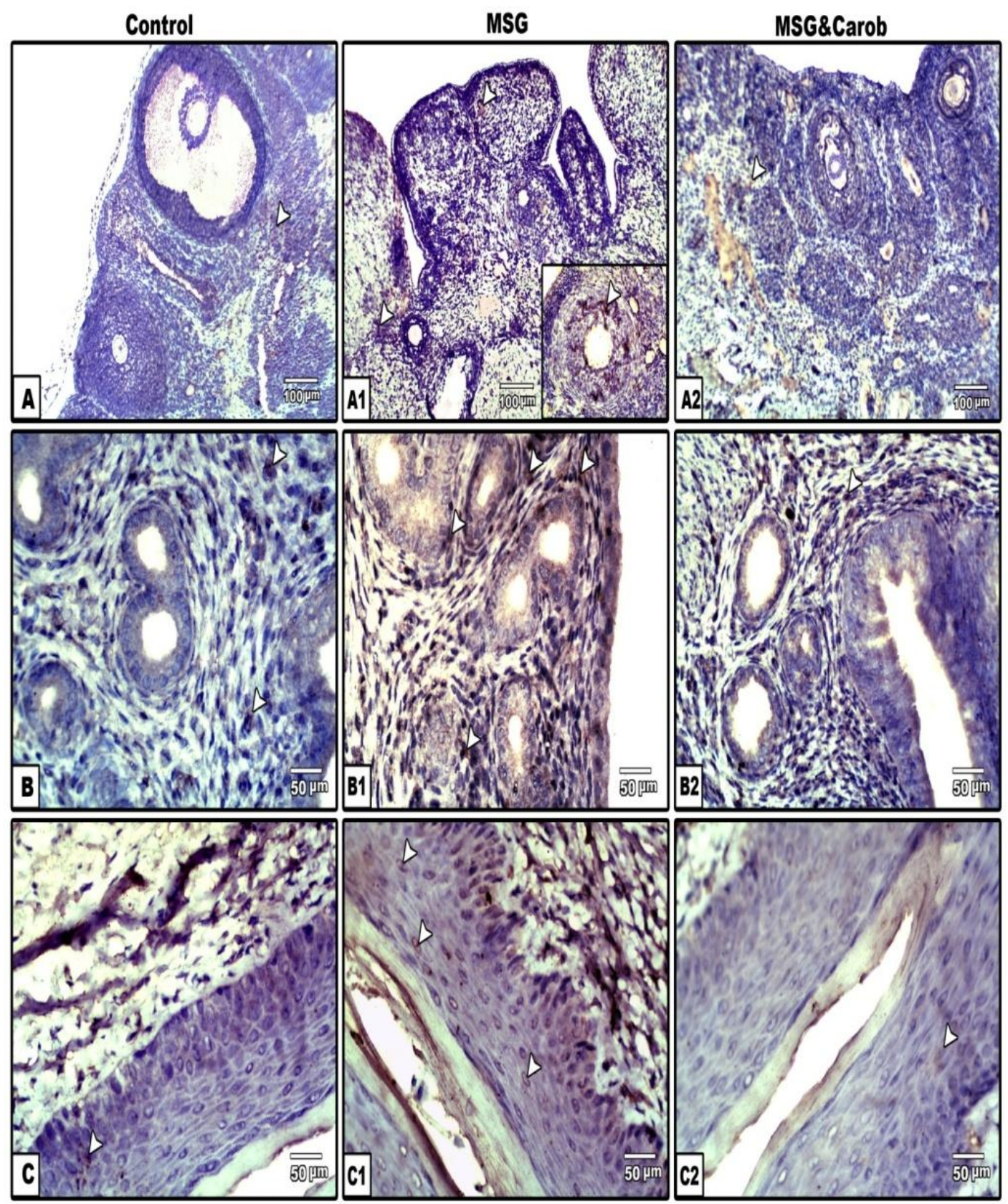

Fig.5

Fig.5.Photomicrographs through the ovarian (A, A1\&A2), uterine (B, B1\&B2) and vaginal $(C, C 1 \& C 2)$ sections of control (A, B\&C), MSG-treatment (A1-C1) and MSG-fed diet containing carob (A2-C2) stained with caspase3 antibody. Note: a weak to moderate reaction for apoptotic cells in sections of control group (A,B\&C) but a strong positive expression for caspase3 in MSG group (A1, B1\&C1). Also, note a remarkable improvement of caspase3 immunoreactivity in the ovary (A2), uterus (B2) and vagina (C2) of MSG-fed diet containing carob. The arrows heads indicate the degree of caspase3 immunoreactivity. 

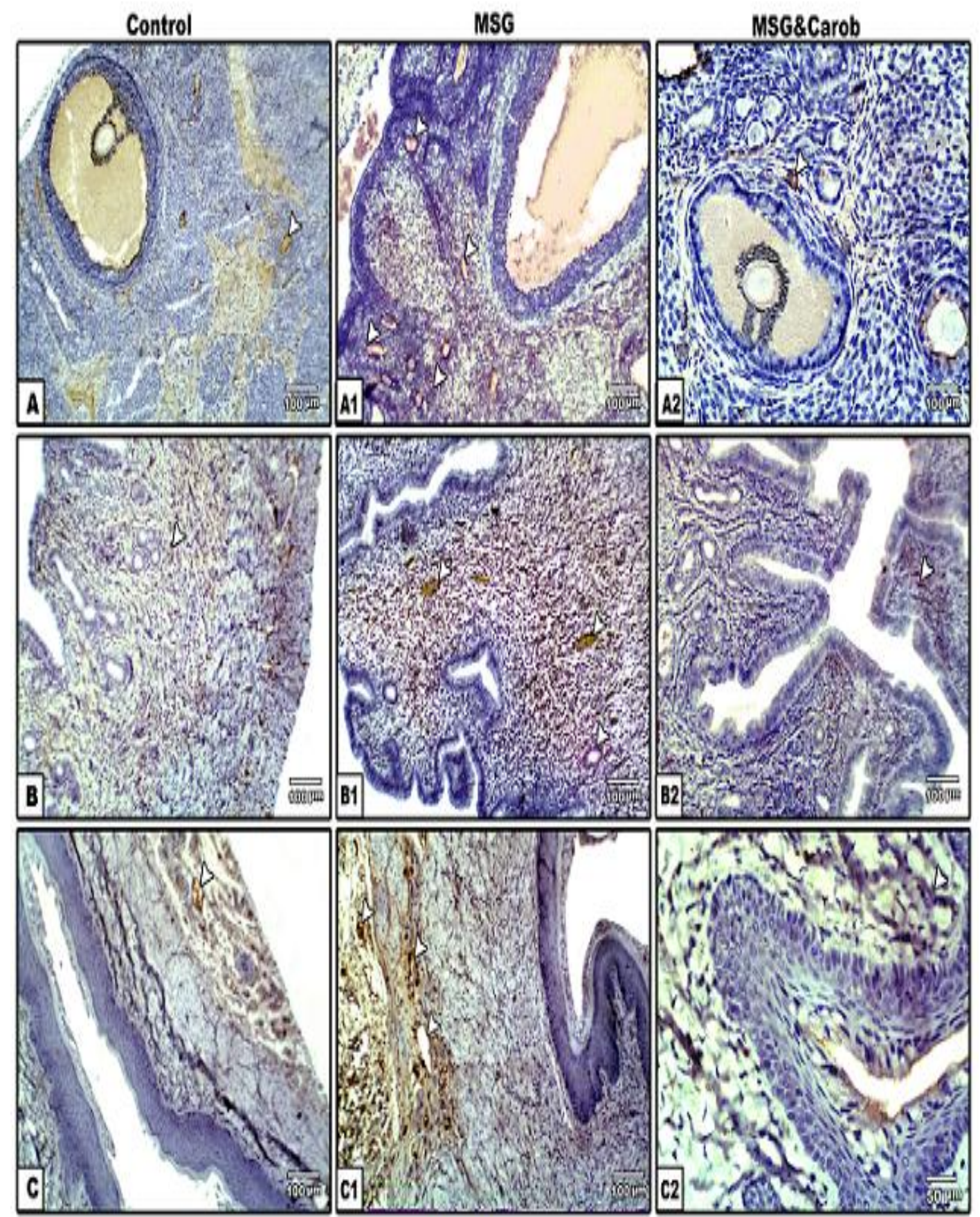

Fia.6

Fig.6.Photomicrographs through the ovarian (A, A1\&A2), uterine (B, B1\&B2) and vaginal (C, C1\&C2) sections of control (A,B, C), MSG-treatment (A1-C1) and MSG-fed diet containing carob(A2-C2) stained with CD31 antibody. Note: a weak to moderate reaction for endothelial cells in sections of control group (A,B\&C) but a strong positive expression for CD31 in MSG group (A1, B1\&C1). Also, note a remarkable improvement of CD31 immunoreactivity in the ovary (A2), uterus (B2) and vagina (C2) of MSG-fed diet containing carob. The arrows heads indicate the degree of CD31 immunoreactivity. 

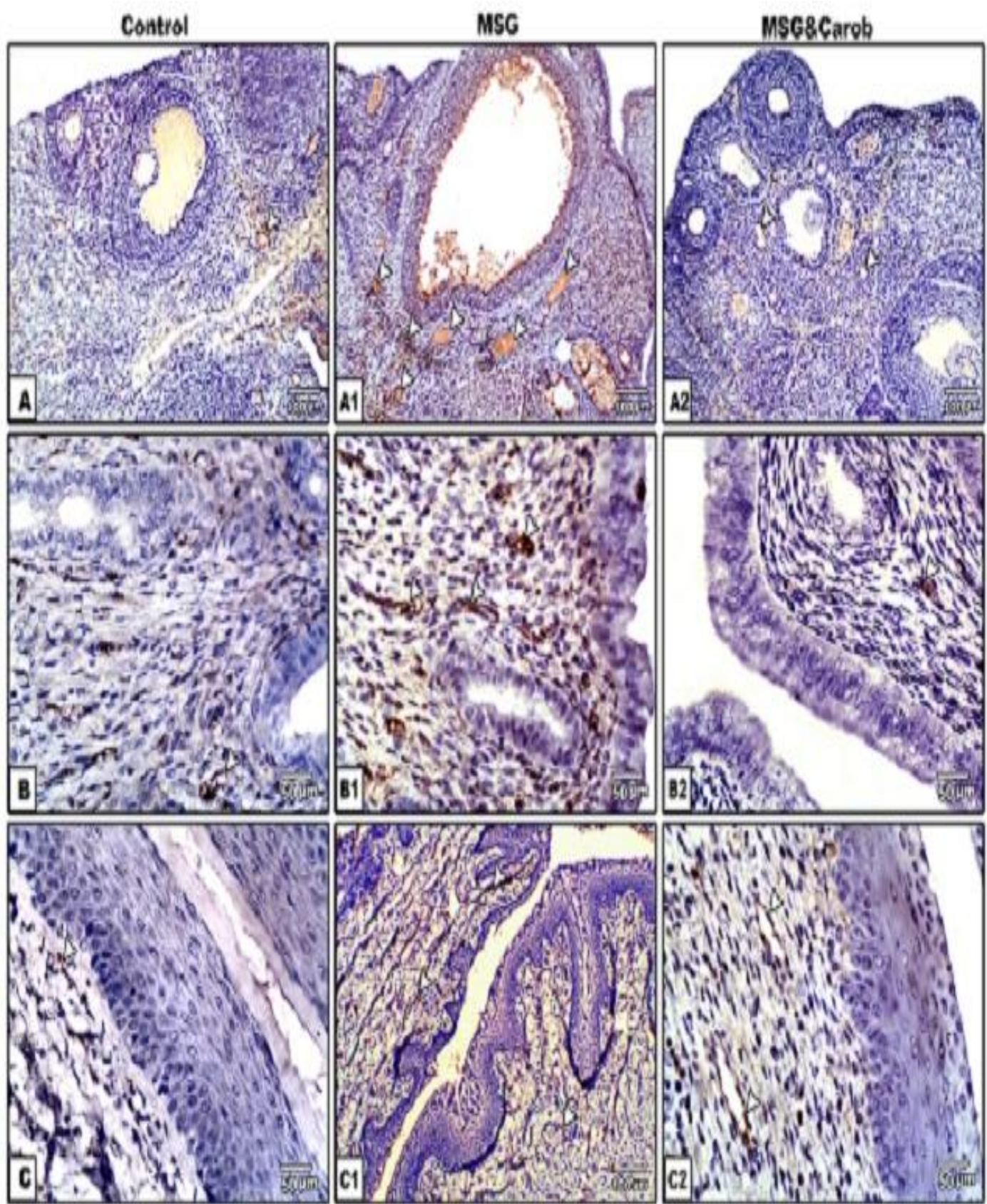

Fig.7

Fig.7. Photomicrographs through the ovarian (A, A1\&A2), uterine (B, B1\&B2) and vaginal (C, C1\&C2) sections of control (A,B, C), MSG-treatment (A1-C1) and MSG-fed diet containing carob(A2-C2) stained with CD68 antibody. Note: a weakly stained monocytes and macrophages in sections of control group (A,B\&C) but an intense expression for CD68 in both of the ovarian (A1) and uterine endometrium (B1) and very weak reaction in the vagina mucosa (C1) of MSG-treated group compared to improved expression in MSG-treated group fed on diet containing carob. The arrows heads indicate the degree of CD68 immunoreactivity.

Cluster of differentiation 31 (CD31) plays an important role identifying vascular invasion through a number of cellular interactions, between endothelial cells and polymorphonuclear leukocytes, monocytes, and lymphocytes during inflammation, as well as during angiogenesis (Muller et al., 2002; Mannelqvist et al., 2009). The present findings revealed that, MSG-treatment led to overexpression of CD31 in endothelial cells of blood vessels in ovaries, uterus and vagina. These findings may result from enhancement of vascular inflammation and increase leakage of leukocytes from the blood vessels into the tissues. Similar observations were reported in female 
reproductive organs of MSG-treated rats (Miśkowiak et al., 2000; Eweka et al., 2010; Oforofuo et al., 2015). Muller et al. (2002) mentioned that endothelial cells play a major role in overcoming inflammation, tissue repair, and angiogenesis.

Cluster of differentiation 68 (CD68) is a glycoprotein expressed in monocyte and macrophage. The present work revealed a comparative increase in immunoreactivity of CD68 in the ovarian stroma and uterine endometrial tissues of MSG- treated rats and less expressed in the vaginal mucosa. Similar findings were observed in the ovarian follicles and stroma of ischemic rats (Balsak et al., 2015). The overexpression of CD68 as a result of MSG-treatment may be attributed to enhanced cellular inflammation and leukocytic infiltration, taking in consideration the abundant distribution of leukocytes in the female reproductive tissues especially polycystic ovaries, endometriosis and premature ovarian failure $(\mathrm{Wu}$ et al., 2004). Sisto et al. (2014) reported that the overexpression of CD68-positive macrophages in the glandular tissues is mainly related to inflammation. Carob represents an important source of polyphones (Kumazawa et al., 2002). Carob extract had ameliorative effect against hepatotoxicity (Rasheed, 2006), nephrotoxicity (Ahmed, 2010) and both cardiac and nephrotoxicity (Hassanein et al., 2015). The improvement of diet containing carob against MSG-treatment may explain the reduction of inflammation, redifferention of ovarian follicle and endometrial gland and decrease of apoptosis and maintain normal pattern of CD31\& CD68. All of these beneficial effects could be attributed to the polyphenol inclusion of carob which has antioxidant capacity.

Conclusion: The authors finally concluded that MSG altered the female reproductive organs (ovaries, uterus and vagina) assessed by histopathological, histochemical and decreases serum estrogen level. However feeding on diet containing carob exerted improvement of structural and function of reproductive organs which may be resulted to phytochemical components improve the metabolism of ovaries, uterus and vagina.

\section{References}

Afeefy, A.A., Marwa, S., Mahmoud, M.S., Arafa, M.A. (2012). Effect of honey on monosodium glutamate induced nephrotoxicity (histological and electron microscopic studies). J Am Sci., 8:146-56.

Ahmed, M.M. (2010). Biochemical Studies on Nephroprotective Effect of Carob (Ceratonia siliqua L.) Growing in Egypt. Nature and Science, 8(3):4147.

Ali,A.A., El-Seify,G.H., El Haroun,H.A., Soliman.,M.A.M.(2014). Effect of monosodium glutamate on the ovaries of adult female albino rats and the possible protective role of green tea. Menoufia Med. Journal., 27:793-800.
AL-Mosaibih,M.A.(2013). Effects of Monosodium Glutamate and Acrylamide on the LiverTissue of Adult Wistar Rats. Life Science Journal., 10(2):35-42.

Avallone, R., Plessi, M., Baraldi,M., Monzani, A. (1997). Determination of chemical composition of carob (Ceratonia siliqua): protein, fat, carbohydrates and tannins. J Food Compost Anal., 10:166-72

Bachmann, G.A., Nevadunsky, N.S.,Johnson, R.W. (2000). Diagnosis and Treatment of Atrophic Vaginitis. Am Fam Physician. 15; 61(10):3090-96.

Balsak, D., Toğrul,C., Ekinci,C., Seçkin,K.D., Karsli,M.F., Ekinci,A ., Tahaoğlu,A.E., Bademkiran,H., Acar,Z., Tun,S.,Y Deveci,E., Kirman, G.(2015). Effects of Melatonin on IschemiaReperfusion Injury in Rat Ovary: Histopathologic andImmunohistochemical Study. Open Journal of Obstetrics and Gynecology, 5, 639-45.

Beyreuther, K., Biesalski, H.K., Fernstrom, J.D., Grimm, P., Hammes, W.P. (2007).Heinemann $\mathrm{U}$, et al. Consensus meeting: monosodium glutamate an update. Eur J Clin Nutr., 61(3):304-13.

Biodun, D., Biodun, A. (1993). Spice or poison? Is monosodium glutamate safe for human consumption? Natl Concord. 4:5.

Bojanic, V., Bojanic, Z., Najman, S., Savic, T., Jakovljevic, V., Najman, S., Jancic, S. (2009). Diltiazem prevention of toxic effects of monosodium glutamate on ovaries in rats. Gen Physiol Biophys., 28:149-54.

Carleton, T. (1980). In: Brenner, B.M., Rector, F.C. (Eds.), Carleton's Histological Tech-nique. , 5th ed. Academic Press, London/New York, Revised and Rewritten byR.A.B. Drury, E.A. Wallington.

Cheville, N.F. (2009). Ultrastructural pathology: the comparative cellular bas of disease. 2nd ed. USA: Wiley-Blackwell. A John Wiley of Sons Inc.

Corsi, L.,Avallone, R., Cosenza, F., Farina, F., Baraldi, C., Baraldi, M. (2002). Antiproliferative effects of Ceratonia siliqua $L$. on mouse hepatocellular carcinoma cell line. Fitoterapia., 73(78):674-84.

Culling, C. F. A., Allison, R. T., Barr, W. T.(1985). Cellular pathology technique., Ed. 4. Butterworths, London, England.

Custódio, L., Fernandes,E., Escapa, L., LópezAvilés, S., Fajardo, A., Aligué, R., Alberício, F., Romano, A. (2009). Antioxidant activity and in vitro inhibition of tumor cell growth by leaf extracts from the carob tree (Ceratonia siliqua). Pharm. Bio. (Formerly Int.J. Pharm.)., 47 (8):721-728.

DeLisser, H.M., Christofidou-Solomidou, M., Strieter, R.M., Burdick, M., Robinson, C.S., Wexler, R.S., Kerr, J.S., et al. (1997). Involvement ofendothelial PECAM-1/CD31 in angiogenesis. Am J Pathol 151:671-77

DeYoung, B.R., Wick, M.R., Fitzgibbon, J.F., Sirgi, K.E., Swanson, P.E. (1993).CD31: an immuno- 
specific marker for endothelial differentiation in human neoplasms. Appl. Immunohistochem. 1:97100

Diniz,Y., Fernando, A., Campos, K., Mani, F., Ribas, B., Novelli, E. (2004). Toxicity of hyper caloric diet and monosodium glutamate: oxidative stress and metabolic shifting in hepatic tissue. Food Chem Toxicol., 42: 319-25.

Edwards, C.A., Blackburn, N.A., Craigen, L., Davison, P., Tomlin, J., Sugden, K., Johnson, I.T., Read, N.W. (1987).Viscosity of food gums determined in vitro related to their hypoglycemic actions.Am J Clin Nutr., 46(1):72-7.

Egbuonu, A., Obidoa, O., Ezeokonkwo, C., Ezeanyika, L., Ejikeme, P. (2009). Hepatotoxic effects of low dose oral administration of monosodium glutamate in male albino rats. Afr $\mathrm{J}$ Biotechnol. 8:3031-5.

El-sherbiny, S.A., El-sayaad., H.J., ELGammal, H.L., EL-sherbiny, E.M. (1995). Effects of difubenzuron and chlorafluazuron on the histological and histochemical structures of the ovary of albino rats. J Egypt Ger Soc Zool.; 17:1-20.

Eweka, A.O., Eweka, A., Om'Iniabohs, F.A.E.(2010). Histological studies of the effects of monosodium glutamate of the fallopian tubes of adult female Wistar rats. North Am.J.of Med.l Sci.2(3):146-49.

Eweka, A.O., Om'iniabohs, F.A.E. (2011). Histological studies of the effects of monosodium glutamate on the ovaries of adult wistar rats. Ann Med. Health Sci. Res., 2, 1:37-44.

Geha, R., Beiser, A., Ren, C., Patterson, R., Grammer, L., Ditto, A.M, Harris, K.E., Shaughnessy, M.A., Yarnold, P.R., Corren. J., Saxon, A. (2001).Review of allergic reaction to monosodium glutamate and outcome of a multicenter double blind placebo-controlled study. J Nutr., 130:1032-8.

Glamoclija,V ., Vilovic,K., Saraga-Babic, M., Baranovic, A., Sapunar, D. (2004). Apoptosis and active caspase-3 expression in human granulosa cells. Fertility and Sterility; 83, (2): 426-31

Gottfried,E., Kunz-Schughartm, L.A., Weber,A., Rehli, M., Peuker, A., Mu ller, A., Kastenberger, M., Brockhoff, G., Andreesen, R., Kreutz, M.(2008). Expression of CD68 in NonMyeloid Cell Types. Scandinavian Journal of Immunology 67, 453-63

Gough, P.J., Gordon, S., Greaves, D.R. (2001).The use of human CD68 tran-scriptional regulatory sequences to direct high-level expression ofclass A scavenger receptor in macrophages in vitro and in vivo. Immunology;103: 351-61

Guggenbichler, J.P.(1983). Adherence of enterobacteria in infantile diarrhea and its prevention. Infection.,11 (4):239-42.

Hassanein, K.M.A., Kamal, M., Youssef, E., Ali, H.M., El Manfaloty,M.M.(2015). The influence of carob powder on lipid profile and histopathology of some organs in rats. Comp Clin Pathol .24:150913

Holnes, C.L., Silva, R.P., Fawcett, J., Gordon, S., Simmons, D.L.(1991). Macrosialin, a mouse macrophage-restricted glycoprotein, is a member of the lamp lgp family. J Biol Chem;268: 9661-6.

Johnston, J.B., Dalal, B.I., Israels, S.J., Oh, S., McMillan, E., Begleiter, A., Michaud, G., Israels, L.G., Greenberg, A.H. (1995). Deposition of transforming growth factor-beta in the marrow in myelofibrosis, and the intracellular localization and secretion of TGF-beta by leukemic cells. American Journal of Clinical Pathology, 103, 574-82.

Joswig, A., Gabriel, H., Kibschull, M.,Winterhager .E.(2003).Apoptosis in uterine epithelium and decidua in response to implantation: evidence for two different pathways.J. Repro. Biol.and Endo.1. (44).1-9.

Klaus,S., Pultz, S., Thone-Reineke, C., Wolfram, S. (2005). Epigallocatechingallate attenuates diet-induced obesity in mice by decreasing energy absorption and increasing fat oxidation. Int. J. Obes. 29:615-23

Kugu, K., Ratts, V.S., Piquette, G.N., Tilly, K.I., Tao, X.J., Martimbeau, S., Aberdeen, G.W., Krajewski, S., Reed, J.C., Pepe, G.J., Albrecht, E.D., Tilly, J.L.(1998). Analysis of apoptosis and expression of bcl-2 gene family members in the human and baboon ovary. Cell Death Differ; 5:67-76.

Kumazawa, S.,Taniguchi, M., Suzuki, Y., Shimura, M., Kwon, M., Nakayama, T. (2002). Agric. Food Chem. 50: 373-377.

Logs, M., W., Esselborg, S.,ScqhulzeOsothoff, K. (1999). The role of caspases in development, immunity, and apoptotic signal transduction: lessons from knockout mice. Immunity., 10:629-39.

Makris, D.P., Kefalos, P. (2004). Carob pods (Ceratonia silique L.) a source of polyphenolic antioxidants. Food Technol Biotechnol. 42:105-108

Mannelqvist,M., Stefansson, I., Salvesen, H.B, et al. (2009). Importance of tumour cell invasion in blood and lymphatic vasculature among patients with endometrial carcinoma. Histopathology., 54:174-83.

Matikainen, T., Perez, G.I., Zheng, T.S., Kluzak,T.R., Rueda, B.R., Flavell, R. et al. (2001). Caspase-3 gene knockout defines cell lineage specificity for programmed cell death signaling in the ovary. Endocrinology; 142:2468-80

Matsumura, T., Wol, K.,Petzelbauer, P. (1997). Endothelial cell tube formation depends on cadherin 5 and CD31 interactions with filamentous actin. J. Immunol. 158:3408-3416

MC Manus, J.F.A. (1948). Histological and histochemical uses of periodic acid. Stain Technology, 23: 99-108.

McCarthy, D.M. (1985). Annotation. Fibrosis of the bone marrow: content and causes. British Journal of Haematology, 59, 1-7. 
Miśkowiak B, Kęsa B, Limanowski A, Patryka M, Filipiak B. (2000).Long term effect of neonatal monosodium glutamate (MSG) treatment on reproductive system of the female rat. Folia Morphol (Praha).58:105-13.

Mobli,M., Qaraaty, M., Amin,G., Haririan I., Hajimahmoodi,M., Rahim,R .(2015). Scientific evaluation of medicinal plants used for the treatment of abnormal uterine bleeding by Avicenna. Arch Gynecol Obstet., 292(1):21-35

Moore, K.L.(2003). Congenital malformations due to environmental. Developing human. 2nd ed. Philadelphia: W.B. Saunders Co. Ltd.,173-83.

Mozes, S., Sefcikova, L., Lenharde, Z., Raeek, L. (2004). Obesity and changes of alkaline phosphatase activity in the small intestine of 40-80 day old subjects to early postnatal overfeeding of monosodium glutamate. Physiol Res. 53:177-86.

Muller,A.M., Hermanns, M.I., Skrzynski, C., Nesslinger, M., Müller, K.M., Kirkpatrick, C.J. (2002). Expression of the endothelial markers PECAM-1, vWf, and CD34 in vivo and in vitro. Exp Mol Pathol. 72:221-9.

Oforofuo, I.C., Adebayo, E.A., Kuye, O.M. (2015). Effects of Monosodium Glutamate in Ovaries of Female Sprague-Dawley Rats Int.J.Curr.Microbiol.App.Sci., 4(5): 737-45.

Oforofuo, O., Onakewhor,J., Idaewor, P. (1997).The effect of chronic administration of MSG on the histology of the adult Wistar rat testes. Biosci Res Commun.,9:2.

Onakewhor, J., Oforofuo, I., Singh, S. (1998). Chronic administration of monosodium glutamate induces oligozoospermia and glycogen accumulation in Wistar rat testes. Afr J Reprod Health.,2(2):190-7.

Ortiz, G.G., Bitzer-Quinter, O.K., Beas Zárate, C., Rodríguez-Reynoso, S., Larios-Arceo, F., Velázquez- Brizuela,I.E, Pacheco-Moisés, F., Rosales-Corral, S.A. (2006). Mono-sodium glutamate-induced damage in liver and kidney: a morphological and bio- chemical approach. Biomed Pharmacother., 60:86-91.

Pandit,L., Ouslander, J.G.(1997). Postmenopausal vaginal atrophy and atrophic vaginitis. Am J Med Sci.,314:228-31.

Papagiannopoulos,M., Wollseifen, H.R., Mellenthin, A., Haber, B., Galensa, R. (2004). Identification and quantification of polyphenols in carob fruits (Ceratonia siliqua L.) and derived products by HPLC-UV-ESI/MS. J. Agric. Food. Chem.,52: 3784-79.

Pavlovic,V., Cekic,S., Kocic, G., Sokolovic, D., Zivkovic,V.(2007). Effect of Monosodium Glutamate on Apoptosis and Bcl-2/Bax Protein Level in Ra Thymocyte Culture. Physiol. Res. 56: 619-626,

Porter, A.G., Janicke,R.U.(1999). Emerging roles of caspase-3 in apoptosis, Cell Death and Diffe; 6: 99- 104.
Rasheed, M.G., A. (2006). phytochemical study of certain Egyptian plants with antioxidant activity.M.Sc. thesis. Faculty of Pharmacy, Cairo Univ., 97-105.

Saito, N., Pulford, K.A., Breton-Gorius, J., Masse, J.M., Mason, D.Y., Cramer, E.M.(1991). Ultrastructural localization of the CD68 macrophageassociated antigen in human blood neutrophils and monocytes. Am J Pathol ;139:1053-9.

Sato,T., Fukazawa, Y., Kojima,H., Enari,M., Iguchi, T., Ohta,Y.(1997). Apoptotic Cell Death during the Estrous Cycle in the Rat Uterus and Vagina. J Anat. Record. 248:76-83.

Seo, H.J., Ham, H.D., Jin, H.Y., Lee, W.H., Hwang, H.S., Park, S.A., Kim, Y.S., Choi, S.C., Lee, S., Oh, K.J., Kim, B.S., Park, B.R., Lee, M.Y.(2010). Chronic administration of monosodium glutamate under chronic variable stress impaired hypothalamicpituitary-adrenal axis function in rats. Korean $\mathrm{J}$ Physiol. Pharmacol. 14:213-21.

Sisto,M., Lisi, S., Ingravallo, G., Lofrumento, D.D., D'Amore, M., Ribatti, D. (2014). Neovascularization is prominent in the chronic inflammatory lesions of Sjögren's syndrome. Int J Exp Pathol., 95(2):131-7.

Tawfik,M.S.,Al-Badr, N. (2012). Adverse Effects of Monosodium Glutamate on Liver and Kidney Functions in Adult Rats and Potential Protective Effect of Vitamins C and E. FNS., 3: 651659.

Tnroh, C., Scqhulze-Osothoff K. (1998). Death by a thou-sand and cuts: an ever increasing list of caspase substrates. Cell Death Differ. 5 5997-1000.

Waer, H.F., Edress, E. (2006).The Effect of Monosodium Glutamate (MSG) On Rat Liver And The Ameliorating Effect Of "Guanidino Ethane Sulfonic acid (GES)” (Histological, Histochemical and Electron Microscopy Studies). Egyp. J Hosp. Med., 24:524 - 538.

Wahyuni, E.D., Situmorang, C.C., Yueniwati,Y., Barlianto, W., Pande Dwijayasa.(M.(2014). Combination of vitamin C and E modulated monosodium glutamate-induced endometrial toxicily in female Wistar rats. Asian Pacific Journal of Reproduction.106-109

Walker, R.L.,upien, J. (2000).The safety evaluation of monosodium glutamate. J Nutr., 130:1049-52.

Wenzl, T.G., Schneider, S., Scheele, F., Silny, J., Heimann, G., Skopnik, H. (2003). Effects of thickened feeding on gastroesophageal reflux in infants: a placebo-controlled crossover study using intraluminal impedance. Pediatrics., 111(4 Pt 1): 3559.

Wu,R., Hoek, K.H., Ryan, N.K., Norman,R.J., Robker,R.L.(2004). Macrophage contributions to ovarian function Human Reproduction Update., 10 (2): 119-33. 
Yousef, J.M. (2011).Study the impacts of monosodium glutamate (MSG) and extract of green tea (theaceae family) leaves induced on kidney biochemical functions in rats. Int J Acad Res., 3:10812.

Zerasky, K.(2010). Nutrition and healthy eating; monosodium glutamate: is it harmful?Available at: http://www.mayoclinic.
Zhou,Z., Christofidou-Solomidou, M., Garlanda, C., DeLisser, H.M (1999). Antibody against murine PECAM-1 inhibits tumor angiogenesis in mice. Angiogenesis 3:181-88

Zia, M.S., Qamar, K., Hanif, R., Khalil, M. (2014). Effect of monosodium glutamate on the serum estrogen and progesterone levels in female rat and prevention of this effect with diltiazem. J Ayub Med Coll Abbottabad., 26(1):18-20. 